\title{
Antimicrobial peptides in saliva of children with severe early childhood caries
}

\author{
Natália H. Colombo a , Laís F.F. Ribas ${ }^{a}$, Jesse A. Pereira ${ }^{a}$, Paula F. Krelinga \\ Christine A. Kressirer ${ }^{\mathrm{b}}$, Anne C.R. Tanner ${ }^{\mathrm{b}, \mathrm{c}}$, Cristiane Duque $^{\mathrm{a}, *}$ \\ ${ }^{a}$ UNESP - Univ. Estadual Paulista, Department of Pediatric Dentistry and Public Health, Araçatuba Dental School, Rua José Bonifácio, 1193, Araçatuba, SP CEP \\ 16015050, Brazil \\ ${ }^{\mathbf{b}}$ The Forsyth Institute, Department of Microbiology, Cambridge, MA, USA \\ c Harvard University, Harvard School of Dental Medicine, Boston, MA, USA
}

\section{A R T I C L E I N F O}

\section{Article history:}

Received 1 September 2015

Received in revised form 25 January 2016

Accepted 8 May 2016

\section{Keywords:}

Human cathelicidin LL-37

Defensins

Histatin-5

Children

Innate immunity

Dental caries

\begin{abstract}
A B S T R A C T
Objective: Controversies exist regarding the relationship between the concentrations of antimicrobial peptides (AMPs) and presence of dental caries in children. Thus, the aim of this study was to examine levels of AMPs in saliva of caries-free (CF), early childhood caries (ECC) and severe early childhood caries (S-ECC) children to determine if the levels of these salivary peptides individually or in combinations were related to caries severity and mutans streptococci levels.

Design: 36 to 60 month-old children were selected to participate in this study. Children were grouped into CF group $(n=29)$, ECC group $(n=25)$ and S-ECC group $(n=29)$. Saliva was collected from children for microbiological analysis by culture. Salivary concentrations of cathelicidin LL-37, human $\beta$-defensin 2 (hBD-2), human $\beta$-defensin 3 (hBD-3) and histatin-5 (HTN-5) were determined by ELISA.

Results: Salivary concentrations of AMPs did not differ among CF, ECC and S-ECC groups. Data showed positive correlations between mutans streptococci levels and salivary hBD-2 or HTN-5. Positive correlations were found between hBD-2, hBD-3, LL-37 and HTN-5. Combinations among AMPs, mainly LL-37, were positively associated with caries levels.

Conclusions: Salivary concentrations of AMPs individually were not associated with the severity of early childhood caries. The stimulus of caries appears to trigger a biological response, however, with a combination of these peptides.
\end{abstract}

(c) 2016 Elsevier Ltd. All rights reserved.

\section{Introduction}

Antimicrobial peptides (AMPs) constitute an important class of molecules belonging to the innate immune system by participating in first line defence reactions at various sites of the human body (Ganz, 2003). AMPs are produced by epithelial tissues, phagocytic cells (Zasloff, 2002), parotid glands and gingival and lateral tongue tissue (Mathews et al., 1999). AMP's exhibit a broad spectrum of activity against bacteria, fungi, and viruses as well as chemotactic activities and induction of cytokine release (Ganz, 2003). In the oral cavity, AMPs are present in saliva, gingival epithelia and gingival crevicular fluid (Joly, Maze, McCray, \& Guthmiller, 2004). Among AMPs, cationic peptides, especially $\alpha$ - and $\beta$-defensins, human cathelicidin LL-37 and histatins have been noted in the

\footnotetext{
* Corresponding author.

E-mail addresses: cristianeduque@yahoo.com.br, cduque@foa.unesp.br (C. Duque).
}

literature for their bactericidal and/or bacteriostatic activities against oral pathogens (Gorr, 2009).

Defensins ( $\alpha$ - and $\beta$ ) are peptides with three disulfide bonds which differ from each other in the spacing and the pairing of the cysteine residues. Alpha-defensins are expressed in neutrophils and have been detected frequently in the gingival crevicular fluid. Beta-defensins (hBD-1, hBD-2 and hBD-3) are expressed in oral epithelial cells and are found in gingival crevicular fluid and in saliva. LL-37, a long cationic alpha-helical peptide from human cathelicidin CAP18, is expressed in neutrophils and epithelial cells and thus present in saliva and gingival crevicular fluid. Histatins are expressed in salivary glands and found in saliva. Histatin 5 is derived from histatin 3 (Ganz, 2003; Joly et al., 2004; Gorr, 2009). Histatin 5 showed potent inhibition against Candida albicans growth and bacterial co-aggregation (Oppenheim et al., 1986). Ouhara et al. (2005) evaluated antimicrobial activity of defensins and LL-37 and reported that six Gram-positive bacteria including, oral streptococci and Lactobacillus casei, showed similar susceptibility to these peptides. Except for hBD-1, all peptides 
demonstrated nearly $100 \%$ bactericidal activity with concentrations less than $10 \mathrm{mg} / \mathrm{l}$.

Some authors have suggested that the reduced concentration of certain peptides could be associated with dental caries in children (Tao et al., 2005; Davidopoulou, Diza, Menexes, \& Kalfas, 2012; Phattarataratip et al., 2011). The levels of $\alpha$-defensin (hNP1-3) (Tao et al., 2005) and LL-37 (Davidopoulou et al., 2012) were lower in saliva from caries-active children compared to caries-free children. Although the antimicrobial properties of $\beta$-defensins have been demonstrated, the literature has not shown differences in the salivary concentrations of these peptides in caries-active compared to caries-free children (Phattarataratip et al., 2011). The salivary concentrations of histatin- 5 in children have not been reported.

Dental caries is an infectious disease that causes the dissolution of tooth mineral by acids derived from bacterial fermentation of dietary carbohydrates (Loesche, 1996). When tooth decay affects deciduous teeth of children under 71 months of age the disease is called early childhood caries (ECC) (American Academy of Pediatric Dentistry, 2014). If the disease progression continues, it may cause the destruction of teeth leading to severe ECC (S-ECC), that has associated local, systemic, psychological and social consequences (Losso, Tavares, Silva, \& Urban, 2009).

There is limited information about the concentration of salivary antimicrobial peptides in children and studies have mainly focused on children with mixed or permanent dentitions. We hypothesized that low salivary levels of AMPs may contribute to caries susceptibility. If so levels of peptides could be a new and useful measure to assess caries risk in children. Thus, we examined the levels of hBD-2, hBD-3, LL-37 and HTN-5 in saliva of caries-free, ECC and S-ECC children, to determine if these salivary peptides were related to caries severity and mutans streptococci levels. This study also examined associations among the severity of ECC and caries-related etiological factors: socio-economic-cultural aspects, dietary habits and colonization by mutans streptococci and lactobacilli.

\section{Material and methods}

\subsection{Subjects}

The study population comprised 36- to 60-month-old children who attended the four public nursery schools in the city of Araçatuba, São Paulo, Brazil. The city's population has access to public water supply with fluoride level of $0.7 \mathrm{ppm}$. Children's parents as well as administrators at the preschools involved granted written permission for the study which was previously approved by the Research Ethics Committee of Univ. Estadual Paulista (UNESP), Brazil (Certificate of Presentation for Ethical Consideration (CAAE) \# 13079213.4.0000.5420).

Questionnaires were given to the parents to complete to assess socio-economic-cultural data and oral hygiene habits. The socioeconomic-cultural data included family income and mother's education. Dietary data were obtained from a food-frequency diary filled out by parents to reflect three consecutive days during the workweek. The diet chart was filled during the workweek because in the weekend the diet can be variable. In addition to the diet data reported by parents, the preschool staff provided information about child feeding in the school period, as many of the children were in school full time. This diet chart included the time of day that the children ate and drank anything and the content of all meals and snacks. The daily frequencies of total sugar exposure and consumption from baby bottles was calculated from chart data (Parisotto et al., 2010).

Clinical examinations were performed at the school by a single calibrated examiner using mouth mirrors and probes under natural light. Decayed, missing and filled surfaces in deciduous teeth (dmfs) were counted in each child. Children suffering from systemic diseases, or using long-term medications or antibiotics less than one month before the examination and children with gingivitis/periodontitis or mucosal lesions were excluded from the study. Children with only restored or missing teeth were also excluded. Initially ninety children from both genders, 36-60 months of age were selected to participate to this study. Seven of the selected children did not attend for saliva collection. So, eightythree children were divided into three groups according to oral health status: caries-free group $(\mathrm{CF})(\mathrm{n}=29)$, early childhood caries group (ECC) $(n=25)$ and severe early childhood caries group (S-ECC) $(n=29)$. ECC was defined for this study as the presence of 1 through 3 decayed tooth surface (cavitated lesions) in primary teeth, S-ECC was defined as the presence of decayed surfaces score of $\geq 4$ (age 3 years), $\geq 5$ (age 4 years), with at least one smoothsurface carious lesion (American Academy of Pediatric Dentistry, 2014). All children with dental caries received dental treatment.

\subsection{Saliva samples}

Unstimulated whole saliva was collected from each subject into a 50-ml sterile falcon conical tubes for 5-10 min. Collections were performed at least $1 \mathrm{~h}$ after feeding to avoid contamination with non-salivary components. Tubes were transported on ice to the laboratory and processed within $1 \mathrm{~h}$. After agitation, one hundred microliters of saliva was separated for microbiological procedures. The remaining saliva was clarified by centrifugation at $10000 \mathrm{rpm}$ at $4{ }^{\circ} \mathrm{C}$ for $10 \mathrm{~min}$. The supernatants were collected and $250 \mathrm{mM}$ EDTA was added to minimize salivary protein aggregation. Aliquots of $100 \mu \mathrm{l}$ of each saliva sample were frozen at $-70^{\circ} \mathrm{C}$ until used for antimicrobial peptide levels measurement by ELISA.

\subsection{Microbiological procedures}

Aliquots of saliva were homogenized by vortexing for $1 \mathrm{~min}$ and the suspensions were serially diluted $\left(10^{-1}\right.$ to $\left.10^{-7}\right)$ in $0.9 \%$ saline solution. Each dilution was cultured in triplicate on the surface of two selective media: Mitis Salivaris Agar (Difco Laboratories, Detroit, MI, USA) with sucrose and bacitracin for isolation of mutans streptococci and Rogosa agar (Oxoid, Basingstoke, Hampshire, England) to detect lactobacilli. All plates were incubated at $37^{\circ} \mathrm{C}$ for $48 \mathrm{~h}$ in air supplemented with $5 \% \mathrm{CO}_{2}$ atmosphere. After $48 \mathrm{~h}$ of incubation, the total colony-forming units (CFU) were counted from a representative area of each agar plate yielding 30-300 colonies using a stereoscopic microscope and the results were expressed as CFU/ml.

\subsection{Antimicrobial peptides level measurement}

The concentration of LL-37, human $\beta$-defensin 2 (hBD-2), human $\beta$-defensin 3 (hBD-3) and human-histatin 5 (HTN-5) in the saliva samples were determined using an enzyme-linked immunosorbent assay (ELISA) kit, specific for each peptide (MyBioSource, Inc., San Diego, CA, USA) following the manufacturer's instructions.

\subsection{Statistical analysis}

The statistical analysis was performed considering three groups of children according to dental caries status (CF, ECC and S-ECC) as the dependent variables. The comparisons among the groups were performed according to data distribution. ANOVA/Tukey tests were applied for caries levels (dmfs), child age and sugar intake. Kruskal-Wallis/Mann-Whitey tests were applied for gender, mother's education level, adult's help with tooth brushing, family 
income, breastfeeding, bottle feeding, mutans streptococci/lactobacilli counts and salivary levels of AMPs. Data were also tested using Pearson or Spearman correlation tests.

\section{Results}

There were no differences in gender between the clinical groups of children (Table 1), or in gender relative to the concentrations of salivary AMPs (Kruskal-Wallis test, $p=0.393$ ). S-ECC families reported a lower income compared to families of CF children. However, no significant difference in maternal education was found between groups. Sugar intake did not differ among the clinical groups, but ECC and S-ECC children were breastfed for longer than $\mathrm{CF}$ children (Table 1 ).

LL-37, hBD-2, hBD-3 and HTN-5 were detected in all saliva samples. Salivary concentration of AMPs did not differ between CF, ECC and S-ECC groups (Fig. 1). There were positive correlations between salivary hBD-2 and HTN-5 levels with salivary mutans streptococci (MS) counts (Fig. 2). There was no relationship between MS levels and other AMPs tested. Lactobacilli counts did not correlate with AMP levels, in part because of high number of children have not detectable lactobacilli. There were weak positive associations between $\mathrm{dmfs}$ and LL-37, and between $\mathrm{dmfs}$ and hBD2 (Table 2). A combination among hBD-2, hBD-3, LL-37 and HTN-5 was also weakly correlated with dmfs (Table 2 ). Further, there were positive correlations among hBD-2, hBD-3 and LL-37. HTN-5 was associated only with LL-37 and hBD-2 (Fig. 3).

\section{Discussion}

The present study shows that there were positive correlations between hBD-2 and HTN-5 with salivary mutans streptococci levels. Malcolm et al. (Malcolm et al., 2014) showed that salivary concentrations of AMPs (HNP1-3 and LL-37) in 3-year-old children were positively correlated with detection of $S$. mutans by qPCR. In contrast, the present study did not find a correlation between LL-37 and mutans streptococci levels. Another association was observed between hBD-2 and LL-37 levels and caries extent (dmfs), which not was not found for HTN-5 and hBD-3. These results suggest that innate immune system of children, represented by antimicrobial peptides, reacted to the presence of S. mutans and their production is increased in the presence of dental caries. In addition, results showed positive correlations between hBD-2, hBD-3, LL-37 and HTN-5 (except for the combination of HTN-5 and hBD-3), suggesting there may be a combined action of these peptides in the host response possibly to caries pathogens since the children studied were healthy except for having dental caries.

Although the present study illustrated a positive correlation between some AMPs and childhood caries (dmfs), the results demonstrated that salivary concentration of the AMP studied did not differ among CF, ECC and S-ECC groups. Our results are in agreement with the studies of Tao et al. (2005) and Phattarataratip et al. (2011). Tao et al. (2005) studied children between 11 and 15 years of age and showed no significant differences in LL-37 and hBD-3 levels in saliva of caries-free compared to caries-active subjects. Phattarataratip et al. (2011) studied 13 year old children and did not find statistically significant differences between salivary levels of LL-37, hBD-2, hBD-3 and hNP-1-3 between cariesfree and caries-active subjects. In contrast, other studies reported lower salivary concentrations of hNP1-3 (Tao et al., 2005) and LL-37 (Davidopoulou et al., 2012) in caries-active compared to caries-free children.

Few studies have associated salivary peptides and caries experience. Most of the literature refers to older children with mixed and permanent dentitions (Tao et al., 2005; Davidopoulou et al., 2012; Phattarataratip et al., 2011). A recent study compared AMPs and bacteria-specific IgA levels in younger children aged 1-3 years and found higher concentrations of hNP-1-3, LL-37, anti-S. mutans IgA and anti-S. sanguinis IgA in children who were culture positive for mutans streptococci compared with those who were culture negative (Malcolm et al., 2014). These associations were not observed in the current study.

Ribeiro et al. (2013) evaluated the protein composition of saliva from 10 to 71 month-old children with and without caries. Identification of molecular masses on chromatograms suggested the presence of nine peptides only three of which were related to caries. The suggested presence of $\alpha$-defensin- 3 and $\beta$-defensin- 3 reduced the chances of detecting caries, whereas the presence of the proline-rich peptide IB- 4 was positively associated with dental caries. In the present study, while individual AMPs did not

Table 1

Characteristics of caries-free, ECC and S-ECC children studied.

\begin{tabular}{|c|c|c|c|c|}
\hline & & $\mathrm{CF}$ & ECC & S-ECC \\
\hline dmfs $($ mean \pm SD) & & $0^{\mathrm{a}}$ & $2.36 \pm 0.95^{\mathrm{b}}$ & $19.34 \pm 14.97^{\mathrm{c}}$ \\
\hline dmfs + white spot $($ mean \pm SD) & & $0^{\mathrm{a}}$ & $2.76 \pm 1.23^{\mathrm{b}}$ & $24.41 \pm 17.94^{\mathrm{c}}$ \\
\hline Age in months (mean \pm SD) & & $48.31 \pm 8.59$ & $49.6 \pm 7.78$ & $50.21 \pm 9.93$ \\
\hline \multirow[t]{2}{*}{ Gender $(\%)$} & Female & 55.2 & 44 & 51.7 \\
\hline & Male & 44.8 & 56 & 48.3 \\
\hline Family income per month (\%) & $<\mathrm{R} \$ 1448.00^{*}$ & $59.3^{\mathrm{A}}$ & $82.6^{\mathrm{A}}$ & $92.6^{\mathrm{B}}$ \\
\hline Mother's education (\%) & Up to 8 years & 20.7 & 24 & 31 \\
\hline Adult help with tooth brushing (\%) & & 72.4 & 68 & 69 \\
\hline \multirow[t]{3}{*}{ Sugar exposure (mean \pm SD) } & Liquid & $4.4 \pm 1.62$ & $5.12 \pm 3.04$ & $4.96 \pm 1.56$ \\
\hline & Solid & $3.71 \pm 1.34$ & $3.64 \pm 1.33$ & $3.27 \pm 1.80$ \\
\hline & Total & $8.12 \pm 2.20$ & $8.76 \pm 3.01$ & $8.23 \pm 2.30$ \\
\hline Breast feeding (\%) & & 79.3 & 88 & 96.4 \\
\hline Bottle feeding (\%) & & 96.6 & 96 & 92.9 \\
\hline Breastfeeding duration in months (mean $\pm S D$ ) & & $5.62 \pm 6.68^{\mathrm{A}}$ & $13.68 \pm 15.77^{\mathrm{B}}$ & $17.21 \pm 12.80^{\mathrm{B}}$ \\
\hline Bottle feeding duration in months (mean $\pm \mathrm{SD}$ ) & & $37.9 \pm 15.96$ & $31.67 \pm 16.72$ & $31.46 \pm 16.77$ \\
\hline Bottle early age (months) (mean \pm SD) & & $5.69 \pm 5.52^{\mathrm{A}}$ & $10.33 \pm 9.83^{B}$ & $13.00 \pm 10.03^{\mathrm{B}}$ \\
\hline $\begin{array}{l}\text { Mutans streptococci count (log CFU + 1) } \\
\text { median (range) }\end{array}$ & Saliva & $4.08(0-6.62)^{\mathrm{A}}$ & $4.05(0-6.41)^{\mathrm{A}}$ & $5.08(0-8.30)^{\mathrm{B}}$ \\
\hline $\begin{array}{l}\text { Lactobaccili count }(\log \mathrm{CFU}+1) \\
\text { median (range) }\end{array}$ & Saliva & $0(0-7.08)$ & $3(0-6.47)$ & $3.7(0-6.88)$ \\
\hline
\end{tabular}

Different lower case letters show statistical difference $(\mathrm{p}<0.05)$ among the groups. according to ANOVA and Tukey tests.

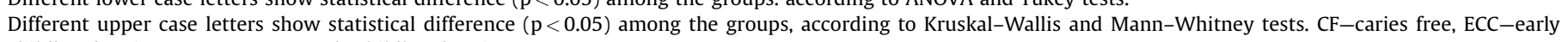
childhood caries, S-ECC-severe early childhood caries.

${ }^{*} \mathrm{R} \$-$ Brazilian real. 1 US\$ $\sim$ R\$ 3.50 (2015, August). 

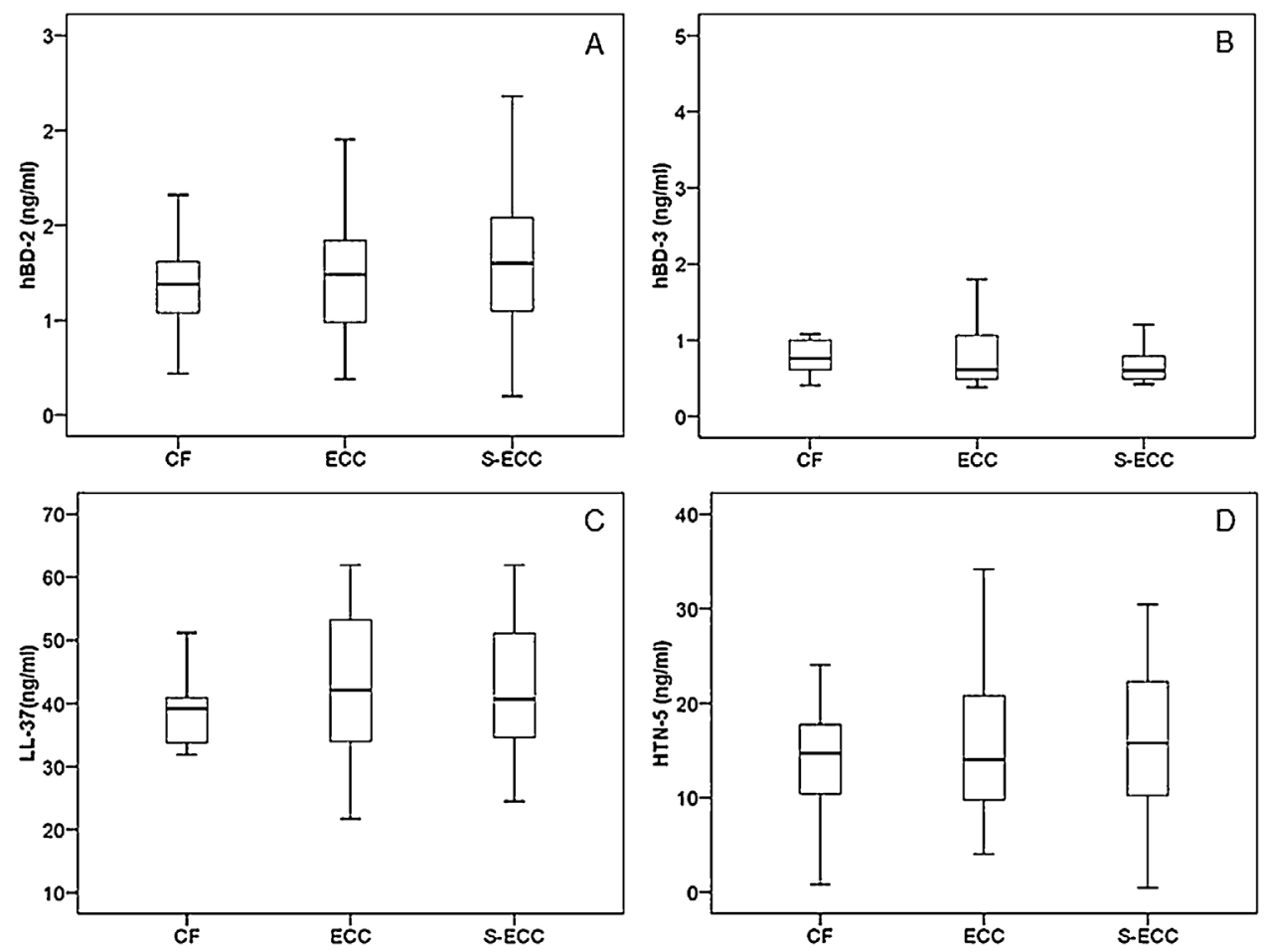

Fig. 1. Levels of antimicrobial peptides (hBD-2, hBD-3, LL-37 and HTN-5) detected in saliva samples of children.

"There was no statistical difference ( $p>0.05$ ) among the groups, considering each AMP separately, according to Kruskal-Wallis tests.

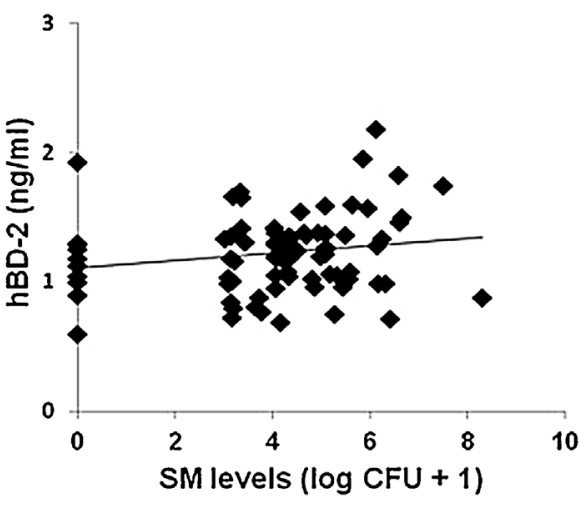

- hBD-2

Linear (hBD-2)

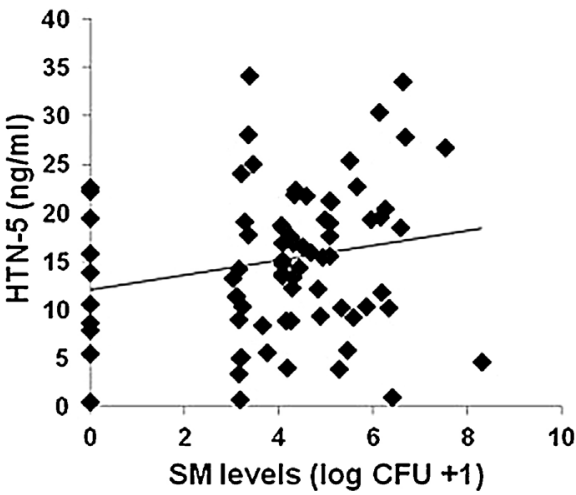

- HTN-5

Linear (HTN-5)

Fig. 2. Relationship between antimicrobial peptides and MS levels. Only significant correlations are shown. (A) Relationship between hBD-2 and salivary mutans streptococci levels (Spearman correlation, $r=0.228, p=0.043$ ). (B) Relationship between HTN-5 and salivary mutans streptococci levels (Spearman correlation, $r=0.235, p=0.039$ ). associated with caries as in the Ribeiro study, correlations among AMPs, mainly with LL-37, were positively correlated with caries levels. These findings suggest a local host reaction to caries in children.

This current report provides the first investigation of salivary concentration of histatin 5 in children. The results showed that the salivary concentration of AMP in children is lower compared to that found in adults (Johnson, Yeh, \& Dodds, 2000; Torres, GarzinoDemo, Meiller, Meeks, \& Jabra-Rizk, 2009). This difference was not surprising considering that the immune system is immature in young children. Johnson and co-workers (Johnson et al., 2000) analyzed saliva of adults and elderly people and showed significant age-associated decreases for histatin concentration suggesting that salivary histatin concentration is reduced with increasing age. Histatins are best known for their antifungal activity. Histatin 5 showed potent antifungal properties including inhibition of growth of C. albicans (Oppenheim et al., 1986). C. albicans is not only involved in fungal infections such as candidiasis, but several studies have demonstrated that this yeast has cariogenic potential (Nikawa et al., 2003; Jin, Samaranayake, Samaranayake, \& Yip, 2004; Falsetta et al., 2014). There is a significant association between the presence of $C$. albicans and early childhood caries. Carvalho et al. (de Carvalho, Silva, Hebling, Spolidorio, \& Spolidorio, 2006) showed that $C$. albicans was significantly more prevalent in early childhood caries than in caries-free children. Considering this information and anti-Candida activity presented by histatin- 5 we expected that the concentration of this peptide could be reduced in children with early childhood caries. However, no difference among the groups was identified in the present study. Our data corroborate with results from Dodds, Johnson, Mobley, and Hattaway (1997) that reported no difference in histatin concentrations from parotid saliva of caries-active and caries-free young adults. Data differ, however, from a recent study that reported increased levels of salivary histatin 5 in young adults ( 18 years old) with high caries activity compared to subjects with low caries activity (Gornowicz et al., 2014). 
Table 2

Relationship between antimicrobial peptides (hBD-2, hBD-3, LL-37 and HTN-5) (individually or in combination) and ECC levels (dmfs score).

\begin{tabular}{lll}
\hline & dmfs & \\
\cline { 2 - 3 } & Pearson correlation & $p$ value \\
\hline hBD-2 & 0.268 & $\mathbf{0 . 0 1 5}$ \\
hBD-3 & -0.189 & 0.102 \\
LL-37 & 0.297 & $\mathbf{0 . 0 0 7}$ \\
HTN-5 & 0.048 & 0.680 \\
hBD-2, hBD-3 & -0.054 & 0.629 \\
hBD-2, LL-37 & 0.307 & $\mathbf{0 . 0 0 5}$ \\
hBD-2, HTN-5 & 0.111 & 0.321 \\
hBD-3, LL-37 & 0.293 & $\mathbf{0 . 0 0 8}$ \\
hBD-3, HTN-5 & 0.088 & 0.432 \\
LL-37, HTN-5 & 0.238 & $\mathbf{0 . 0 3 1}$ \\
hBD-2, hBD-3, LL-37 & 0.295 & $\mathbf{0 . 0 0 7}$ \\
hBD-2, hBD-3, HTN-5 & 0.095 & 0.395 \\
hBD-3,LL-37, HTN-5 & 0.231 & $\mathbf{0 . 0 3 7}$ \\
hBD-2,LL-37, HTN-5 & 0.240 & $\mathbf{0 . 0 3 0}$ \\
LL-37, hBD-2, hBD-3, HTN-5 & 0.232 & $\mathbf{0 . 0 3 6}$ \\
\hline
\end{tabular}

Bold values are lower than 0.05 (significant correlation between antimicrobial peptides and ECC levels - dmfs score).
Early childhood caries is a multifactorial disease caused by oral bacteria and influenced by various social and behavioral factors (Arora, Schwarz, \& Blinkhorn, 2011; Ng and Chase, 2013; CorrêaFaria, Martins-Júnior, Vieira-Andrade, Marques, \& Ramos-Jorge, 2013). In the present study most S-ECC children were from families with lower incomes compared to CF children. This observation is in accordance with studies of Oliveira, Sheiham, and Bönecker (2008) and Corrêa-Faria et al. (2013) that found a higher prevalence of dental caries in children from low-income families. Oliveira et al. (2008) also reported that children whose mothers had less than 8 years of education presented the highest prevalence of dental caries. However, in this study, no significant difference in maternal education was found among groups.

High frequency of dietary sugar was strongly associated with dental caries (Parisotto et al., 2010; Kalsbeek \& Verrips, 1994; Milgrom et al., 2000). However, the present study did not find significant differences in sugar intake among the groups. Our results corroborate the results of Ohlund et al., (2007) who reported that caries experience was not correlated with dietary sugar. The answers from parents about sugar intake may have

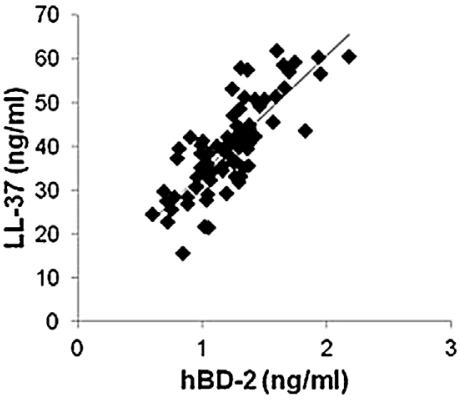

+ LL-37

— Linear (LL-37)

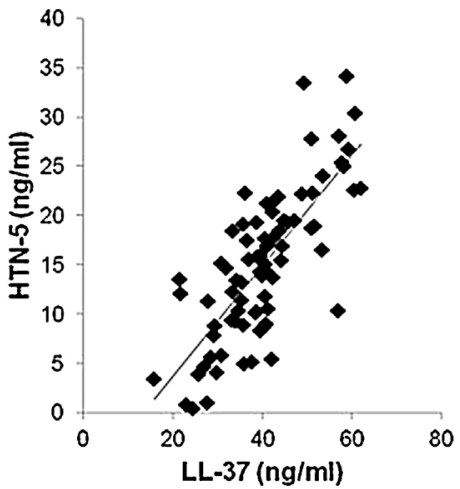

- HTN-5

- Linear (HTN-5)

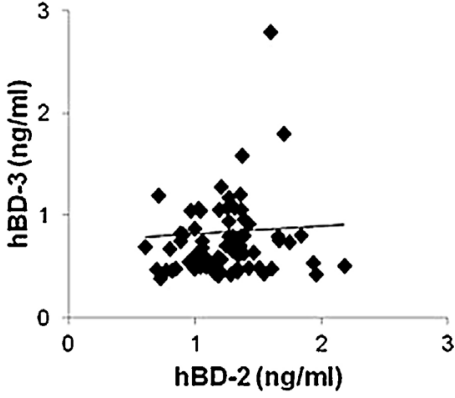

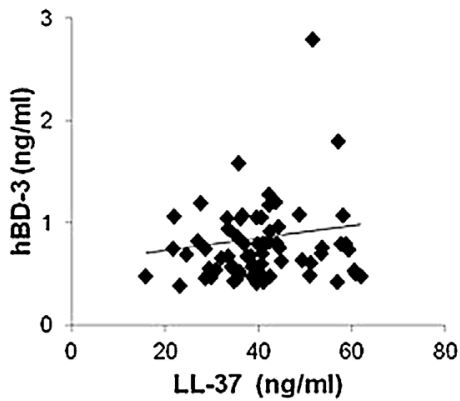

- hBD-3

- Linear (hBD-3)

- hBD-3

- Linear (hBD-3)

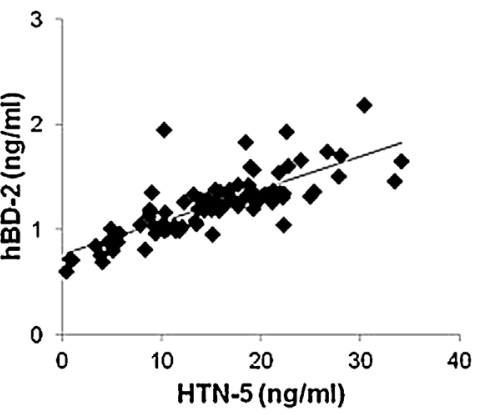

c

$+\mathrm{hBD}-2$

- Linear (h8D-2)

Fig. 3. Relationship between the antimicrobial peptides studied. Only significant correlations are shown. (A) Relationship between LL-37 and hBD-2 (Spearman correlation, $r=0.831, p=0.000$ ). (B) Relationship between HTN-5 and LL-37 (Spearman correlation, $r=0.765, p=0.000$ ). (C) Relationship between hBD-2 and HTN-5 (Spearman correlation, $r=0.796, p=0.000$ ). (D) Relationship between hBD-3 and LL-37 (Spearman correlation, $r=0.188, p=0.053$ ). (E) Relationship between $h B D-3$ and $h B D-2$ (Spearman correlation, $r=0.193, p=0.048$ ). 
reflected diet at the time of the visit, not the previous diet experience during the period of caries onset. Additionally, some parents may minimize the sweet consumption by their children when reporting to questionnaires.

Although the eating habits did not differ among caries groups at the time of the visit, survey data indicated that ECC and S-ECC children were breastfed for longer than CF children. No statistical difference among the groups was observed for the bottle feeding time. This result provides evidence of the association of prolonged breastfeeding and early childhood caries as described by Azevedo, Bezerra, and de Toledo (2005) who reported that breastfeeding after 1 year of age was associated with ECC. Kato et al. (2015) conducted a longitudinal study with more than 43,000 babies and found an association between breastfeeding for at least 6 or 7 months and risk of dental caries at age 30 months. Prolonged breastfeeding may be associated with ECC because many mothers know the benefits of breast milk, such as the presence of antibodies (secretory IgA) for baby protection against a variety of diseases, but they often unaware that it also may cause tooth decay, and thus neglect oral hygiene of their babies after breastfeeding. Bowen and Lawrence (2005), using an animal model, showed that while human milk is more cariogenic than cow's milk, human milk is no more cariogenic than are common infant formulas. This may partially explain why children with a longer breastfeeding exposure time have a higher caries index. The quality of oral hygiene is related to caries development, but this study only evaluated tooth-brushing frequency not efficiency. No difference among caries groups was found based on brushing frequency.

The S-ECC children had higher mutans streptococci levels in saliva compared with ECC and CF children consistent with high levels of salivary mutans streptococci (MS) especially S. mutans, being a significant risk factor for the presence of childhood caries (Milgrom et al., 2000; Ohlund et al., 2007; Ge, Caufield, Fisch, \& Li, 2008). Children with a high levels of MS have 5 times greater risk to develop dental caries than children with a lower MS levels (Milgrom et al., 2000).

Caries risk prediction has long been of interest and is very important for development of new strategies for caries prevention. This is especially significant for young children. In this present study, among caries-related etiological factors analyzed, a reduced family income and prolonged period of breastfeeding were associated with S-ECC. This present study does not support the measurement of salivary levels of LL-37, hBD-2, hBD-3 and histatin 5 as a reliable tool to predict caries risk. Thus, salivary concentrations of these AMPs were not associated with severity of early childhood caries. As a consequence of this clinical study, it is not possible to conclude that there is an association between caries risk and AMP levels. Longitudinal studies are necessary to evaluate if initial salivary AMP levels are beneficial in reducing caries risk.

\section{Conflict of interest}

None.

\section{Acknowledgements}

This study was supported by grants (2012/19235-5; 2013/ 12167-7) from São Paulo Research Foundation (FAPESP), São Paulo, SP, Brazil and Coordination for the Improvement of Higher Education Personnel (CAPES).

\section{References}

American Academy of Pediatric Dentistry, Council on Clinical Affairs (2014). Policy on early childhood caries (ECC): classifications, consequences, and preventive strategies. Oral Health Policies50-52.

Arora, A., Schwarz, E., \& Blinkhorn, A. S. (2011). Risk factors for early childhood caries in disadvantaged populations. Journal of Investigative and Clinical Dentistry, 2(4), $223-228$.

Azevedo, T. D., Bezerra, A. C., \& de Toledo, O. A. (2005). Feeding habits and severe early childhood caries in Brazilian preschool children. Pediatric Dentistry, 27(1), 28-33.

Bowen, W. H., \& Lawrence, R. A. (2005). Comparison of the cariogenicity of cola, honey, cow milk, human milk, and sucrose. Pediatrics, 116(4), 921-926.

Corrêa-Faria, P., Martins-Júnior, P. A., Vieira-Andrade, R. G., Marques, L. S., \& RamosJorge, M. L. (2013). Factors associated with the development of early childhood caries among Brazilian preschoolers. Brazilian Oral Research, 27(4), 356-362.

Davidopoulou, S., Diza, E., Menexes, G., \& Kalfas, S. (2012). Salivary concentration of the antimicrobial peptide LL-37 in children. Archives of Oral Biology, 57(7), 865869.

de Carvalho, F. G., Silva, D. S., Hebling, J., Spolidorio, L. C., \& Spolidorio, D. M. (2006). Presence of mutans streptococci and Candida spp: in dental plaque/dentine of carious teeth and early childhood caries. Archives of Oral Biology, 51(11), 10241028.

Ganz, T. (2003). Defensins antimicrobial peptides of innate immunity. Nature Reviews Immunology, 3(9), 710-720.

Dodds, M. W., Johnson, D. A., Mobley, C. C., \& Hattaway, K. M. (1997). Parotid saliva protein profiles in caries-free and caries-active adults. Oral Surgery, Oral Medicine, Oral Pathology, Oral Radiology and Endodontics, 83(2), 244-251.

Falsetta, M. L., Klein, M. I., Colonne, P. M., Scott-Anne, K., Gregoire, S., Pai, C. H., et al. (2014). Symbiotic relationship between Streptococcus mutans and Candida albicans synergizes virulence of plaque biofilms in vivo. Infection and Immunity, 82(5), 1968-1981.

Ge, Y., Caufield, P. W., Fisch, G. S., \& Li, Y. (2008). Streptococcus mutans and Streptococcus sanguinis colonization correlated with caries experience in children. Caries Research, 42(6), 444-448.

Gornowicz, A., Tokajuk, G., Bielawska, A., Maciorkowska, E., Jabłoński, R., Wójcicka, A., et al. (2014). The assessment of sIgA, histatin-5, and lactoperoxidase levels in saliva of adolescents with dental caries. Medical Science Monitor, 20,1095-1100.

Gorr, S. U. (2009). Antimicrobial peptides of the oral cavity. Periodontology 2000, 51, $152-180$.

Jin, Y., Samaranayake, L. P., Samaranayake, Y., \& Yip, H. K. (2004). Biofilm formation of Candida albicans is variably affected by saliva and dietary sugars. Archives of Oral Biology, 49(10), 789-798.

Johnson, D. A., Yeh, C. K., \& Dodds, M. W. (2000). Effect of donor age on the concentrations of histatins in human parotid and submandibular/sublingual saliva. Archives of Oral Biology, 45(9), 731-740.

Joly, S., Maze, C., McCray, P. B., \& Guthmiller, J. M. (2004). Human beta-defensins 2 and 3 demonstrate strain-selective activity against oral microorganisms. Journal of Clinical Microbiology, 42(3), 1024-1029.

Kalsbeek, H., \& Verrips, G. H. (1994). Consumption of sweet snacks and caries experience of primary school children. Caries Research, 28(6), 477-483.

Kato, T., Yorifuji, T., Yamakawa, M., Inoue, S., Saito, K., Doi, H., \& Kawachi, I. (2015). Association of breastfeeding with early childhood dental caries: Japanese population-based study. BMJ Open, 5, e006982. http://dx.doi.org/10.1136/ bmjopen-2014-006982.

Loesche, W. J. (1996). Microbiology of dental decay and periodontal disease, In S. Baron (Ed.), Medical Microbiology4th edition Galveston (TX): University of Texas Medical Branch at Galveston.

Losso, E. M., Tavares, M. C., Silva, J. Y., \& Urban, CeA. (2009). Severe early childhood caries: an integral approach. Jornal de Pediatria, 85(4), 295-300.

Malcolm, J., Sherriff, A., Lappin, D. F., Ramage, G., Conway, D. I., Macpherson, L. M., et al. (2014). Salivary antimicrobial proteins associate with age-related changes in streptococcal composition in dental plaque. Molecular Oral Microbiology.

Mathews, M., Jia, H. P., Guthmiller, J. M., Losh, G., Graham, S., Johnson, G. K., et al. (1999). Production of beta-defensin antimicrobial peptides by the oral mucosa and salivary glands. Infection and Immunity, 67(6), 2740-2745.

Milgrom, P., Riedy, C. A., Weinstein, P., Tanner, A. C., Manibusan, L., \& Bruss, J. (2000). Dental caries and its relationship to bacterial infection, hypoplasia, diet, and oral hygiene in 6- to 36-month-old children. Community Dentistry and Oral Epidemiology, 28(4), 295-306.

Ng, M. W., \& Chase, I. (2013). Early childhood caries: risk-based disease prevention and management. Dental Clinics of North America, 57(1), 1-16.

Nikawa, H., Yamashiro, H., Makihira, S., Nishimura, M., Egusa, H., Furukawa, M., et al. (2003). In vitro cariogenic potential of Candida albicans. Mycoses, 46(11-12), $471-478$.

Ohlund, I., Holgerson, P. L., Backman, B., Lind, T., Hernell, O., \& Johansson, I. (2007). Diet intake and caries prevalence in four-year-old children living in a lowprevalence country. Caries Research, 41(1), 26-33.

Oliveira, L. B., Sheiham, A., \& Bönecker, M. (2008). Exploring the association of dental caries with social factors and nutritional status in Brazilian preschool children. European Journal of Oral Sciences, 116(1), 37-43.

Oppenheim, F. G., Yang, Y. C., Diamond, R. D., Hyslop, D., Offner, G. D., \& Troxler, R. F. (1986). The primary structure and functional characterization of the neutral histidine-rich polypeptide from human parotid secretion. Journal of Biological Chemistry, 261(3), 1177-1182. 
Ouhara, K., Komatsuzawa, H., Yamada, S., Shiba, H., Fujiwara, T., Ohara, M., et al. (2005). Susceptibilities of periodontopathogenic and cariogenic bacteria to antibacterial peptides, \{beta\}-defensins and LL37, produced by human epithelial cells. Journal of Antimicrobial Chemotherapy, 55(6), 888-896.

Parisotto, T. M., Steiner-Oliveira, C., Duque, C., Peres, R. C., Rodrigues, L. K., \& Nobredos-Santos, M. (2010). Relationship among microbiological composition and presence of dental plaque, sugar exposure, social factors and different stages of early childhood caries. Archives of Oral Biology, 55(5), 365-373.

Phattarataratip, E., Olson, B., Broffitt, B., Qian, F., Brogden, K. A., Drake, D. R., et al. (2011). Streptococcus mutans strains recovered from caries-active or caries-free individuals differ in sensitivity to host antimicrobial peptides. Molecular Oral Microbiology, 26(3), 187-199.
Ribeiro, T. R., Dria, K. J., de Carvalho, C. B., Monteiro, A. J., Fonteles, M. C., de Moraes Carvalho, K., et al. (2013). Salivary peptide profile and its association with early childhood caries. International Journal of Paediatric Dentistry, 23(3), 225-234.

Tao, R., Jurevic, R. J., Coulton, K. K., Tsutsui, M. T., Roberts, M. C., Kimball, J. R., et al. (2005). Salivary antimicrobial peptide expression and dental caries experience in children. Antimicrobial Agents and Chemotherapy, 49(9), 3883-3888.

Torres, S. R., Garzino-Demo, A., Meiller, T. F., Meeks, V., \& Jabra-Rizk, M. A. (2009). Salivary histatin-5 and oral fungal colonisation in HIV+ individuals. Mycoses, 52 (1), 11-15.

Zasloff, M. (2002). Innate immunity, antimicrobial peptides, and protection of the oral cavity. Lancet, 360(9340), 1116-1117. 